\title{
BMJ Open Application of a Common Data Model (CDM) to rank the paediatric user and prescription prevalence of 15 different drug classes in South Korea, Hong Kong, Taiwan, Japan and Australia: an observational, descriptive study
}

Ruth Brauer (D) , ${ }^{1}$ lan Chi Kei Wong, ${ }^{1,2}$ Kenneth KC Man (D) , ${ }^{1,2}$ Nicole L Pratt, ${ }^{3}$ Rae Woong Park, ${ }^{4}$ Soo-Yeon Cho, ${ }^{4}$ Yu-Chuan (Jack) Li, ${ }^{5,6,7,8}$ Usman Iqbal, ${ }^{6,9,10}$ Phung-Anh Alex Nguyen, ${ }^{6}$ Martijn Schuemie (D) ${ }^{11,12}$

To cite: Brauer R, Wong ICK Man KKC, et al. Application of a Common Data Model (CDM) to rank the paediatric user and prescription prevalence of 15 different drug classes in South Korea, Hong Kong, Taiwan, Japan and Australia: an observational, descriptive study. BMJ Open 2020;10:e032426. doi:10.1136/ bmjopen-2019-032426

- Prepublication history and additional material for this paper are available online. To view these files, please visit the journal online (http://dx.doi. org/10.1136/bmjopen-2019032426).

Received 27 June 2019 Revised 03 December 2019 Accepted 04 December 2019

Check for updates

(C) Author(s) (or their employer(s)) 2020. Re-use permitted under CC BY-NC. No commercial re-use. See rights and permissions. Published by BMJ.

For numbered affiliations see end of article.

Correspondence to Professor lan Chi Kei Wong; i.wong@ucl.ac.uk

\section{ABSTRACT}

Objective To measure the paediatric user and prescription prevalence in inpatient and ambulatory settings in South Korea, Hong Kong, Taiwan, Japan and Australia by age and gender. A further objective was to list the most commonly used drugs per drug class, per country.

Design and setting Hospital inpatient and insurance paediatric healthcare data from the following databases were used to conduct this descriptive drug utilisation study: (i) the South Korean Ajou University School of Medicine database; (ii) the Hong Kong Clinical Data Analysis and Reporting System; (iii) the Japan Medical Data Center; (iv) Taiwan's National Health Insurance Research Database and (v) the Australian Pharmaceutical Benefits Scheme. Country-specific data were transformed into the Observational Medical Outcomes Partnership Common Data Model.

Patients Children ( $\leq 18$ years) with at least 1 day of observation in any of the respective databases from January 2009 until December 2013 were included. Main outcome measures For each drug class, we assessed the per-protocol overall user and prescription prevalence rates (per 1000 persons) per country and setting.

Results Our study population comprised 1574524 children (52.9\% male). The highest proportion of dispensings was recorded in the youngest age category (<2 years) for inpatients (45.1\%) with a relatively high user prevalence of analgesics and antibiotics. Adrenergics, antihistamines, mucolytics and corticosteroids were used in $10 \%-15 \%$ of patients. For ambulatory patients, the highest proportion of dispensings was recorded in the middle age category (2-11 years, $67.1 \%$ ) with antibiotics the most dispensed drug overall.

Conclusions Country-specific paediatric drug utilisation patterns were described, ranked and compared between four East Asian countries and Australia. The widespread use of mucolytics in East Asia warrants further investigation.
Strengths and limitations of this study

- We conducted the largest Western Pacific paediatric drug utilisation study to date using a Common Data Model, which allowed us to rank the user and prescription prevalence of 15 different drug classes in South Korea, Hong Kong, Taiwan, Japan and Australia.

- Our comprehensive overview of country-specific pharmacological agents used in both an ambulatory and inpatient setting, by gender and age, included data of 1574524 children and identified important differences in drug paediatric utilisation patterns.

- Despite the differences in databases in terms of setting and study populations, we believe our overview of prescription patterns and rankings is an important step to further investigate and facilitate the rational use of drugs in paediatric populations in East Asia and Australia.

- Over the counter prescribing in individual countries was not captured and we may have underestimated the true drug utilisation of agents, such as paracetamol and some antihistamines.

- We collected data until the end of 2013 and acknowledge that, due to the rapid change in paediatric licensing of therapeutic agents, some of our findings might be worthwhile replicating with more current data.

\section{INTRODUCTION}

An important step to facilitate the rational use of drugs in paediatric populations is to investigate drug utilisation patterns. ${ }^{1}$ Observational data in the form of electronic health records (EHR) and insurance claims data, real-life data, have been used successfully to investigate the use of drugs in children. ${ }^{1-3}$ European studies on paediatric drug 
utilisation patterns have shown that the most commonly used drugs in European children include anti-infective, respiratory and dermatological drugs and are largely prescribed off-label. ${ }^{3}$ While drug-specific paediatric drug utilisation data from East Asian countries are available, ${ }^{4-6}$ a comprehensive overview of the most commonly used drugs is currently lacking.

The Asian Pharmacoepidemiology Network, the first multinational research network in Asia, in collaboration with the Observational Medical Outcome Partnership (OMOP) set up an initiative to convert domestic databases in Asian countries to a Common Data Model $(\mathrm{CDM})$ to offer a multinational research infrastructure to facilitate studies. ${ }^{78}$ We used this network of observational healthcare databases in South Korea, Hong Kong, Taiwan, Japan and Australia to measure and compare the prevalence of drug prescribing in East Asian and Australian children. Our primary aim was to measure the paediatric user and prescription prevalence in inpatient and ambulatory settings in the five aforementioned countries by age and gender. A further objective was to list the most commonly used drugs per drug class, per country, in both an inpatient and ambulatory setting.

\section{METHODS}

\section{Data sources}

We conducted a drug utilisation study using paediatric patient populations from the following databases: (i) Ajou University School of Medicine (AUSOM) from South Korea; (ii) the Hong Kong Clinical Data Analysis and Reporting System (CDARS); (iii) the Japan Medical Data Center (JMDC); (iv) Taiwan's National Health Insurance Research Database (NHIRD) and (v) the Australian Pharmaceutical Benefits Scheme (PBS). All data were anonymised to protect patient confidentiality.

All five countries have universal healthcare systems and none of the databases include information on patients using private healthcare. ${ }^{7}$ The South Korean and Hong Kong databases, AUSOM and CDARS, collect and archive the EHR of hospital inpatients. Briefly, AUSOM is an EHR database of a Korean teaching hospital providing both secondary and tertiary care, with 1096 patient beds and 23 operating rooms with data for over 2073120 individuals, collected since 1994. By contrast, CDARS contains secondary care data from all public hospitals in Hong Kong and their associated ambulatory and primary care clinics since $1995 .^{9-11}$ The database was developed and is maintained by the Hong Kong Hospital Authority, a statutory body providing healthcare services available to all Hong Kong residents (over 7 million) and covering about $80 \%$ of all hospital admissions.

The Japanese, Taiwanese and Australian data were extracted from insurance research databases. The Japanese JMDC comprises data from 60 Society-Managed Health Insurances covering workers aged 18-65 years and their dependents (children and elderly). ${ }^{12}$ The monthly claims data are derived from claims issued by clinics, hospitals and community pharmacies from July 2009 onwards. Australian data consist of national pharmacy claims data from the Australian Government Department of Human Services which provides information of medicines subsidised and dispensed under the Pharmaceutical Benefits Scheme. PBS data are collected from pharmacies and private hospitals, and discharge or outpatient dispensing from public hospitals, but do not include inpatient public hospital prescriptions. From Taiwan, we extracted reimbursement data from the Bureau National Health Insurance (NHI) system, which has registered all medical claims since 1995. More than $99 \%$ of the citizens of Taiwan are enrolled in the NHI, which offers mandatory and comprehensive medical care coverage to all Taiwanese residents.

Information on specific indications of drug use was not available in the datasets from Hong Kong, Taiwan and Japan. Further details of each database have been described elsewhere. ${ }^{13}$

\section{Data collection}

For this retrospective descriptive study, we identified children, 18 years or younger, with at least 1 day of observation in any of the respective databases. The follow-up period for all children started in January 2009 or the start date of observation, whichever was last. Follow-up ended in December 2013, the last date observation or the date a child turned 18, whichever was first. Specifically, observation time was defined as: 1) the start of the first visit (inpatient, outpatient or emergency room) to the end of the last visit for the Korean AUSOM database; 2) the date of birth until death in the Hong Kong CDARS database and 3) the insurance enrolment date in the Japan JMDC, Taiwan NHIRD and Australian PBS. Data were available from the end of 2009 onwards for the Japanese JMDC and until December 2011 for the Taiwanese database (NHIRD). We used randomly selected samples from CDARS, NHIRD and PBS as only $10 \%$ of the total data were made available for research.

\section{Data extraction}

Data extraction, a population file with information on demographics and dispensing records, was performed through a shared analysis programme combining $\mathrm{R}$ and SQL. This programme was distributed to the data partners, executed locally against the data in OMOP CDM format and results were returned to the central coordinating site (University of Hong Kong). Both the extraction software and the analysis code are available as open source: https://github.com/OHDSI/StudyProtocols/tree/master/DrugsInPeds

Each database's full set of drug codes were mapped to RxNorm concepts using a semi-automated process; using known ATC codes for each code, a set of one or more RxNorm ingredients was identified based on the OMOP Standardised Vocabularies link between ATC and RxNorm. In case of ambiguity, manual adjudication was used to select the appropriate RxNorm ingredient. 


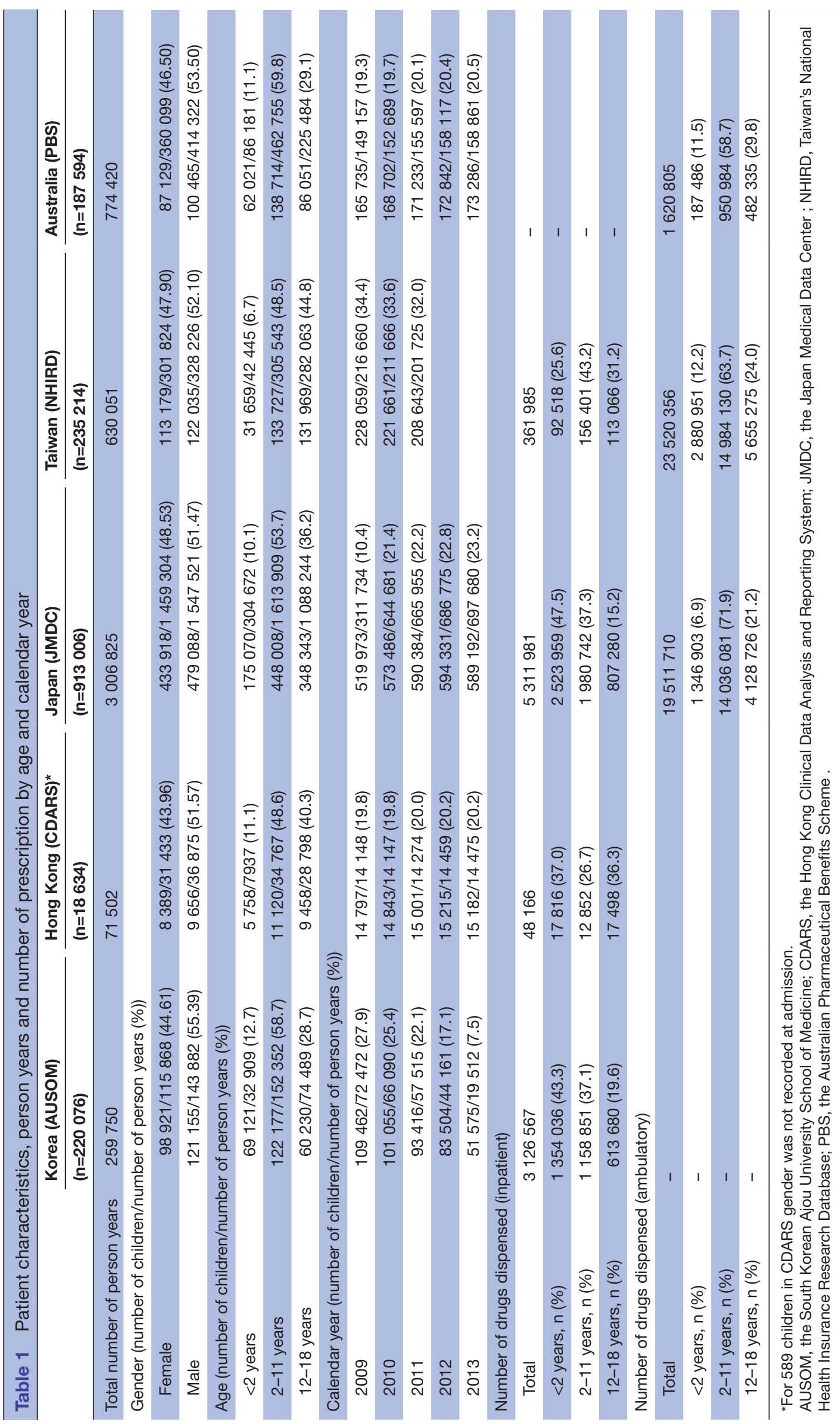


Table 2 User prevalence and prescription prevalence and in an inpatient setting by therapeutic level: prevalence per 1000 persons

\begin{tabular}{|c|c|c|c|c|c|c|c|c|}
\hline \multirow[b]{2}{*}{ Class* $^{*}$} & \multicolumn{2}{|c|}{ Korea (AUSOM) } & \multicolumn{2}{|c|}{ Hong Kong (CDARS) } & \multicolumn{2}{|c|}{ Japan (JMDC) } & \multicolumn{2}{|c|}{ Taiwan (NHIRD) } \\
\hline & $\begin{array}{l}\text { User } \\
\text { prevalence } \\
(\%) \dagger \\
\end{array}$ & $\begin{array}{l}\text { Prescription } \\
\text { prevalence } \\
(\%) \ddagger\end{array}$ & $\begin{array}{l}\text { User } \\
\text { prevalence } \\
(\%) \dagger \\
\end{array}$ & $\begin{array}{l}\text { Prescription } \\
\text { prevalence }(\%) \ddagger\end{array}$ & $\begin{array}{l}\text { User } \\
\text { prevalence } \\
(\%) \dagger \\
\end{array}$ & $\begin{array}{l}\text { Prescription } \\
\text { prevalence } \\
(\%) \ddagger\end{array}$ & $\begin{array}{l}\text { User } \\
\text { prevalence } \\
(\%) \dagger\end{array}$ & $\begin{array}{l}\text { Prescription } \\
\text { prevalence } \\
(\%) \ddagger\end{array}$ \\
\hline Antibiotics & $107(22)$ & $1141(20)$ & $91(25)$ & $634(37)$ & $43(26)$ & $496(31)$ & $37(21)$ & $233(27)$ \\
\hline Mucolytics & $53(11)$ & $614(11)$ & $4(1)$ & $7(0)$ & $22(13)$ & $168(11)$ & $19(11)$ & $69(8)$ \\
\hline Corticosteroids & $45(9)$ & $425(8)$ & $21(6)$ & $89(5)$ & $15(9)$ & $89(6)$ & $18(10)$ & $72(8)$ \\
\hline $\begin{array}{l}\text { Anti-infectives } \\
\text { (excluding antibiotics } \\
\text { and vaccines) }\end{array}$ & $9(2)$ & $130(2)$ & $14(4)$ & $48(3)$ & $2(1)$ & $28(2)$ & $2(1)$ & $15(2)$ \\
\hline Antidiabetic drugs & $4(1)$ & $19(0)$ & $0(0)$ & $7(0)$ & $1(1)$ & $4(0)$ & $1(1)$ & $5(1)$ \\
\hline $\begin{array}{l}\text { Psychotherapeutic } \\
\text { agents }\end{array}$ & $2(0)$ & $65(1)$ & $3(1)$ & $138(8)$ & $2(1)$ & $17(1)$ & $1(1)$ & $14(2)$ \\
\hline $\begin{array}{l}\text { Antineoplastic and } \\
\text { immunomodulating } \\
\text { agents }\end{array}$ & $2(0)$ & $100(2)$ & $1(0)$ & $61(4)$ & $1(1)$ & $26(2)$ & $0(0)$ & $14(2)$ \\
\hline $\begin{array}{l}\text { Central nervous system } \\
\text { stimulants }\end{array}$ & $1(0)$ & $20(0)$ & $2(1)$ & $62(4)$ & $0(0)$ & $2(0)$ & $0(0)$ & $3(0)$ \\
\hline Contraceptives & $0(0)$ & $2(0)$ & $0(0)$ & $0(0)$ & $0(0)$ & $0(0)$ & $0(0)$ & $0(0)$ \\
\hline Total & 473 (100\%) & $5614(100 \%)$ & 360 (100\%) & 1697 (100\%) & 167 (100\%) & 1587 (100\%) & 173 (100\%) & 852 (100\%) \\
\hline
\end{tabular}

${ }^{*}$ Custom classification, see online supplementary material 1.

†For all 15 different drug classes, the prevalence per 1000 persons was calculated as \% of the total country-specific user prevalence (class-specific user prevalence/total user prevalence).

†For all 15 different drug classes, the prevalence per 1000 persons was calculated as \% of the total country-specific prescription prevalence (class-specific prescription prevalence/total prescription prevalence).

AUSOM, the South Korean Ajou University School of Medicine; CDARS, the Hong Kong Clinical Data Analysis and Reporting System; JMDC, the Japan Medical Data Center ; NHIRD, Taiwan's National Health Insurance Research Database; NSAID, non-steroidal anti-inflammatory drug.

Structured information on strength and formulation was used to further link drug codes to RxNorm clinical drugs (eg, 'Paracetamol $100 \mathrm{mg}$ Oral Tablet'), although this more granular information was not used in this study.

\section{Patient and public involvement}

We did not involve patients or the public in our work.

\section{Statistical analysis}

Total follow-up time was calculated for each child, stratified by age group and by calendar year. Age was assessed on a day-by-day basis, and grouped according to the guidelines of the International Conference of Harmonization as $<2$ years, $2-11$ years and $12-18$ years. ${ }^{14}$ Drugs were classified according to a custom-defined drug classification (online supplementary material 1 ). This classification was based on pharmacological class, and where appropriate aggregated further by indication. For each drug class, we assessed the overall user and prescription prevalence rates (per 1000 persons) per country and setting (inpatient or ambulatory) by counting the number of children using or number of dispensings of a specific drug (numerator). We used the total person count per database and per setting (inpatient or ambulatory) as the denominator to calculate prevalence rates. If a person was observed for at least 1 day in a particular category (eg, age group), that person was counted in the denominator for that category. Over the study period, and within a calendar year, children could contribute to more than one age category. For all 15 different custom drug classes the prevalence per 1000 persons was calculated as the percentage of the total country-specific user prevalence (class-specific user prevalence/total user prevalence). Lastly, we identified the five drugs with the highest user prevalence (per 1000 persons) per drug class in each country.

\section{RESULTS}

\section{Study population}

Our dynamic study cohort comprised 1574524 children $(52.9 \%$ male). The total number of follow-up years was 
Table 3 User prevalence and prescription prevalence and in an ambulatory setting by therapeutic level (prevalence per 1000 persons)

\begin{tabular}{|c|c|c|c|c|c|c|}
\hline \multirow[b]{2}{*}{ Class* } & \multicolumn{2}{|c|}{ Japan (JMDC) } & \multicolumn{2}{|c|}{ Taiwan (NHIRD) } & \multicolumn{2}{|c|}{ Australia (PBS) } \\
\hline & $\begin{array}{l}\text { User } \\
\text { prevalence } \\
(\%) \dagger\end{array}$ & $\begin{array}{l}\text { Prescription } \\
\text { prevalence } \\
(\%) \ddagger\end{array}$ & $\begin{array}{l}\text { User } \\
\text { prevalence } \\
(\%) \dagger\end{array}$ & $\begin{array}{l}\text { Prescription } \\
\text { prevalence }(\%) \ddagger\end{array}$ & $\begin{array}{l}\text { User } \\
\text { prevalence } \\
(\%) \dagger\end{array}$ & $\begin{array}{l}\text { Prescription } \\
\text { prevalence } \\
(\%) \ddagger\end{array}$ \\
\hline Antibiotics & $440(22)$ & $882(25)$ & $796(14)$ & 2010 (8) & $679(46)$ & $918(52)$ \\
\hline Corticosteroids & $401(20)$ & $954(27)$ & 701 (13) & $1352(6)$ & $348(23)$ & $281(16)$ \\
\hline $\begin{array}{l}\text { Analgesics (including } \\
\text { NSAIDs) }\end{array}$ & $333(16)$ & $428(12)$ & $933(17)$ & $5889(24)$ & $96(6)$ & $61(3)$ \\
\hline Adrenergics & $242(12)$ & $405(11)$ & $814(15)$ & 4666 (19) & $184(12)$ & $193(11)$ \\
\hline Antihistamines & 261 (13) & $415(12)$ & $883(16)$ & $6246(26)$ & $3(0)$ & $1(0)$ \\
\hline Mucolytics & $240(12)$ & $353(10)$ & $756(14)$ & 3053 (13) & $0(0)$ & $0(0)$ \\
\hline $\begin{array}{l}\text { Anti-infectives } \\
\text { (excluding antibiotics } \\
\text { and vaccines) }\end{array}$ & $91(4)$ & $60(2)$ & $490(9)$ & $842(3)$ & $72(5)$ & $25(1)$ \\
\hline Contraceptives & $1(0)$ & $1(0)$ & $23(0)$ & $17(0)$ & $34(2)$ & $27(2)$ \\
\hline $\begin{array}{l}\text { Psychotherapeutic } \\
\text { agents }\end{array}$ & $2(0)$ & $7(0)$ & $23(0)$ & $41(0)$ & $33(2)$ & $86(5)$ \\
\hline $\begin{array}{l}\text { Central nervous } \\
\text { system stimulants }\end{array}$ & $3(0)$ & $5(0)$ & $20(0)$ & $65(0)$ & $25(2)$ & $117(7)$ \\
\hline $\begin{array}{l}\text { Antineoplastic and } \\
\text { immunomodulating } \\
\text { agents }\end{array}$ & $4(0)$ & $7(0)$ & $9(0)$ & $15(0)$ & $1(0)$ & $3(0)$ \\
\hline Antiepileptics & $2(0)$ & $5(0)$ & $15(0)$ & $44(0)$ & $6(0)$ & $41(2)$ \\
\hline $\begin{array}{l}\text { Anticlotting and } \\
\text { antifibrinolytic agents }\end{array}$ & $3(0)$ & $2(0)$ & $13(0)$ & $10(0)$ & $1(0)$ & $2(0)$ \\
\hline Diuretics & $0(0)$ & $1(0)$ & $4(0)$ & $5(0)$ & $2(0)$ & $2(0)$ \\
\hline Antidiabetic drugs & $0(0)$ & $1(0)$ & $2(0)$ & $8(0)$ & $3(0)$ & $5(0)$ \\
\hline Total & 2023 (100\%) & 3526 (100\%) & $5482(100 \%)$ & 24263 (100\%) & 1487 (100\%) & 1762 (100\%) \\
\hline
\end{tabular}

${ }^{*}$ Custom classification, see online supplementary material 1.

†For all 15 different drug classes, the prevalence per 1000 persons was calculated as \% of the total country-specific user prevalence (classspecific user prevalence/total user prevalence).

łFor all 15 different drug classes, the prevalence per 1000 persons was calculated as \% of the total country-specific prescription prevalence (class-specific prescription prevalence/total prescription prevalence).

JMDC, the Japan Medical Data Center ; NHIRD, Taiwan's National Health Insurance Research Database; NSAID, non-steroidal antiinflammatory drug; PBS, the Australian Pharmaceutical Benefits Scheme.

4783549 years, with a mean individual follow-up of 3.0 years. The database that contributed most person years to the study was the Japanese JDMC (58\%) (table 1). Altogether, we recorded close to 9 million paediatric inpatient dispensings (8 848 699) and $>44$ million ambulatory dispensings (44 652 871). The relative number of dispensings prescribed per age category differed between the inpatient and ambulatory patient settings, with the highest proportion of dispensings recorded in the youngest age category ( $<2$ years) for inpatients $(45.1 \%)$ and in the middle age category (2-11 years) for ambulatory patients $(67.1 \%)$.

\section{User and prescription prevalence}

The recorded user and prescription prevalence of all therapeutic agents was lower in the inpatient population than the ambulatory population (tables 2 and 3 ).
Analgesics (including non-steroidal anti-inflammatory drugs) had the highest user prevalence in Korea, Hong Kong and Taiwan in the inpatient setting, however, antibiotics had the highest prescription prevalence in most countries (Hong Kong, Japan and Taiwan). In the ambulatory setting, antibiotics had the highest user prevalence in all countries, however, the highest prescription prevalence differed across countries. In Japan, the highest prescription prevalence was recorded for corticosteroids, while in Taiwan the highest prescription prevalence was for antihistamines and lastly, in Australia the highest prevalence was recorded for antibiotics.

\section{Inpatient user and prescription prevalence}

Overall, the inpatient user prevalence of analgesics and antibiotics was high relative to the user prevalence of other agents in all countries (table 2). Adrenergics, 


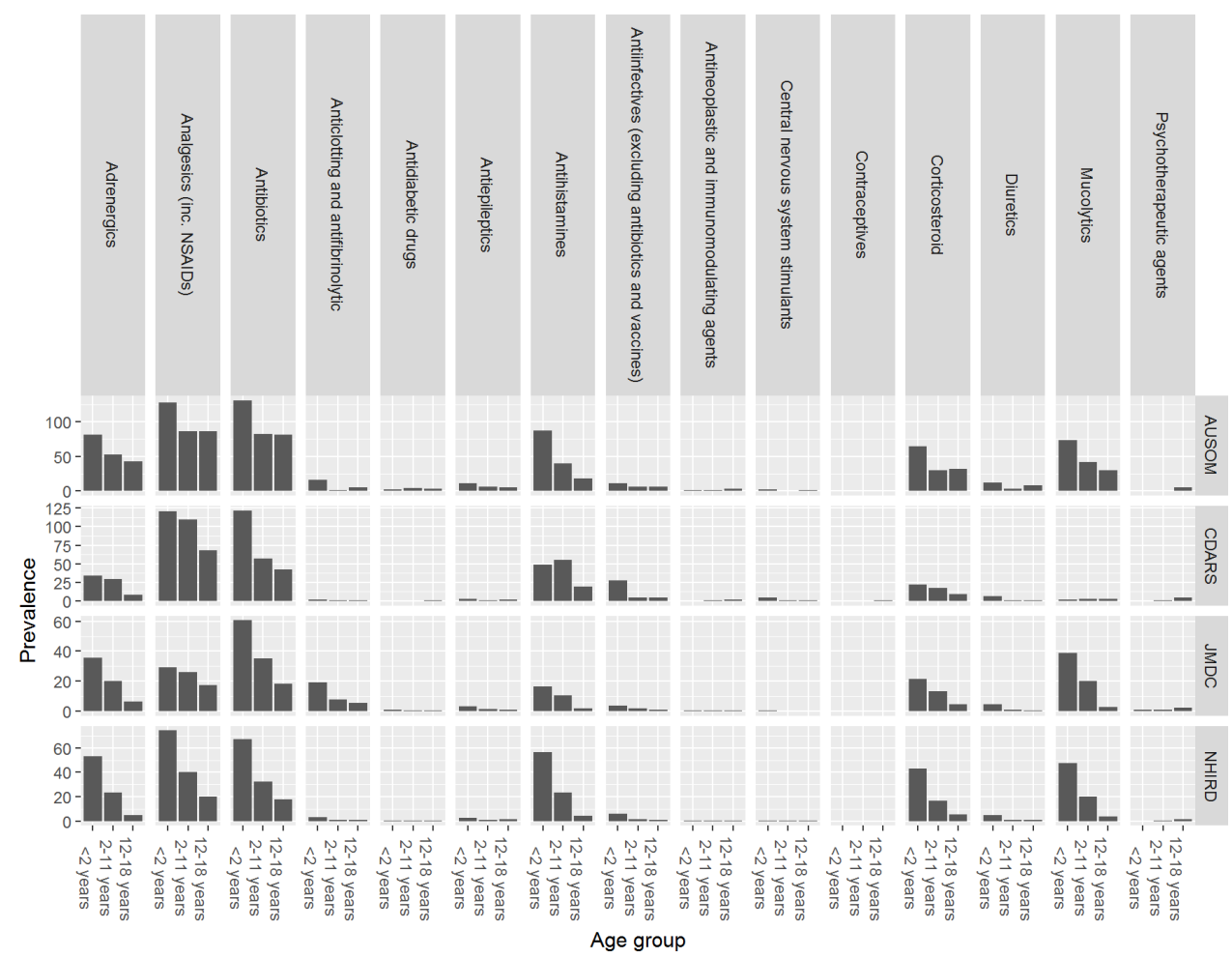

Figure 1 User prevalence by therapeutic level (prevalence per 1000 persons) and age in an inpatient setting. NSAID, nonsteroidal anti-inflammatory drug.

antihistamines, mucolytics and corticosteroids were used in $10 \%-15 \%$ of patients while the remaining categories of medicines were used in $<5 \%$ of patients. The user prevalence of mucolytics in Korea and Japan was high compared with the user prevalence of other agents. Inpatient prescription prevalence for different classes of agents showed patterns similar to those seen for the user prevalence.

For paediatric inpatients, overall medication use was highest in males (online supplementary material 2). The use of contraceptives, antidiabetic, psychotherapeutic, antineoplastic and immunomodulating agents was more common in females.

Results stratified by age show that the inpatient use of drugs was highest in the youngest age group ( $<2$ years) in all but four classes (contraceptives, antidiabetic, psychotherapeutic, antineoplastic and immunomodulating agents) (figure 1).

\section{Ambulatory user and prescription prevalence}

The paediatric use of different classes of drugs in an ambulatory setting was measured in Japan, Taiwan and Australia (table 3). The highest ambulatory user prevalence across all drug classes was country specific with antibiotics ranked high in Japan (22\%) and Australia (46\%), followed by corticosteroids (20\% and $23 \%$, respectively). In Taiwan, the highest user prevalence of any drug class was measured for analgesics $(17 \%)$, closely followed by antihistamines $(16 \%)$. The pattern of inpatient prescription prevalence for different classes of agents was similar to the pattern seen for the user prevalence. A very low prescription prevalence of anti-infectives (not including antibiotics) was measured in all countries.

The ambulatory dispensing of drugs stratified by gender showed fewer differences between males and females in all databases (figure 2). In contrast to the gender difference seen in an inpatient setting, the ambulatory use of antibiotic agents, antihistamines and corticosteroids was higher in females.

The user prevalence by age showed a very different pattern when compared with inpatient use: the use of most drugs, by class, was highest in the middle age category (2-11 years) in Japan and Australia (online supplementary material 3). For Taiwan, the highest use for many drug classes was measured in the youngest age category. The use of contraceptives, antidiabetic, psychotherapeutic, antineoplastic and immunomodulating agents was highest in the oldest age group across all three databases.

\section{Most commonly used drugs by class in an inpatient setting}

Paracetamol was the most prevalent analgesic used in all countries, however, the prevalence of paracetamol users differed across countries with Hong Kong and Japan using mostly paracetamol while Korea and Taiwan had a greater spread of analgesic product use (table 4). Phenobarbital was the most prescribed antiepileptic agent in three countries and the second most prescribed antiepileptic agent in Taiwan. Chlorpheniramine was one of the most used antihistamines in all countries with the exception of Japan.

Differences in the most used paediatric drugs in an inpatient setting were seen for drugs with a high user 


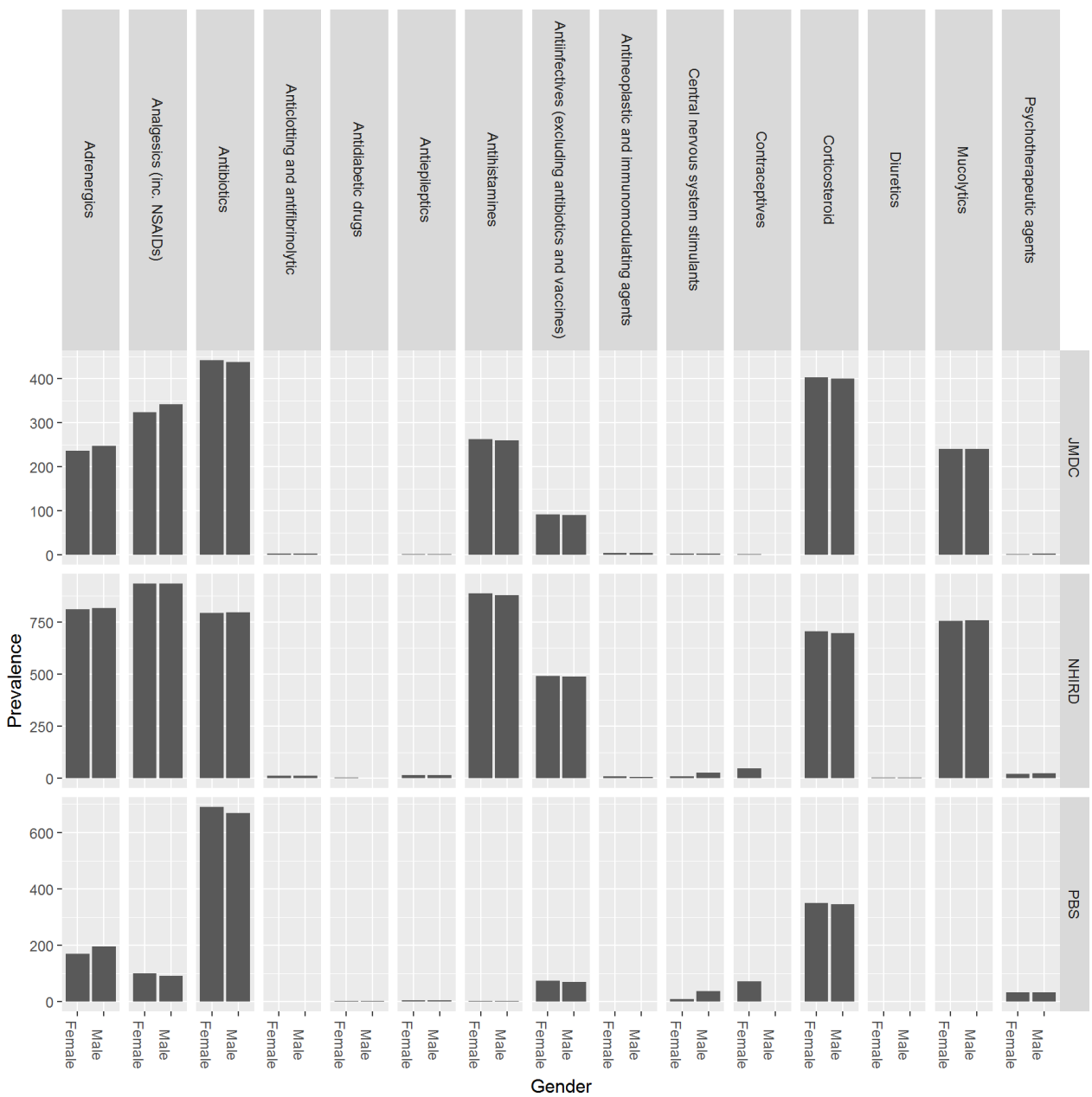

Figure 2 User prevalence by therapeutic level (prevalence per 1000 persons) and gender in an ambulatory setting. NSAID, non-steroidal anti-inflammatory drug.

prevalence overall, such as antibiotic and adrenergic agents. An outlying pattern of the user prevalence for specific agents was seen in South Korea: the most used antibiotic (ceftriaxone) and adrenergic agent (formoterol) in Korea were not among the five drugs with the highest inpatient user prevalence in any of the other East Asian countries. Furthermore, the most used mucolytic (bromhexine) and corticosteroid (dexamethasone) in Korea were less frequently used in other countries.

\section{Most commonly used drugs by class in an ambulatory setting}

As in the inpatient setting, the most used analgesic in an ambulatory setting in Japan, Taiwan and Australia was paracetamol (table 5). Overall, more similarities in the most commonly used drugs per custom-defined drug class were seen between Japan and Taiwan. For antibiotic agents, the use of amoxicillin, cephalexin and erythromycin was very similar in Taiwan and Australia. For other drug classes there was less overlap.

\section{DISCUSSION}

To our knowledge, this is the first comprehensive overview of paediatric drug use in Korea, Hong Kong, Japan, Taiwan and Australia. This study has shown a high inpatient user prevalence of analgesics and antibiotics relative to the user prevalence of other drug classes. The highest ambulatory user prevalence across all drug classes was country specific with antibiotics and corticosteroids ranked high in Japan and Australia. In Taiwan, the user prevalence of analgesics was highest followed by antihistamines. Mucolytics were among the most frequently used drugs in Korea, Japan and Taiwan, but not in Hong Kong and Australia. For paediatric inpatients, medication use was highest in males and the lowest age category $(<2$ years), while for outpatients gender differences were less pronounced and medication use was highest in children aged 2-11 years in Japan and Australia.

\section{Comparison with literature}

While we used a custom therapeutic classification and not ATC classification, the most commonly used drugs in every class were compared with those as reported by Sturkenboom et al..$^{3}$ Overall, the choice of specific paediatric therapeutic agents differed widely between the aforementioned three European countries and the East Asian countries in our study. Exceptions were similarities in the use of amoxicillin, salbutamol and paracetamol. The inpatient study results (tables 2 and 4) were compared 


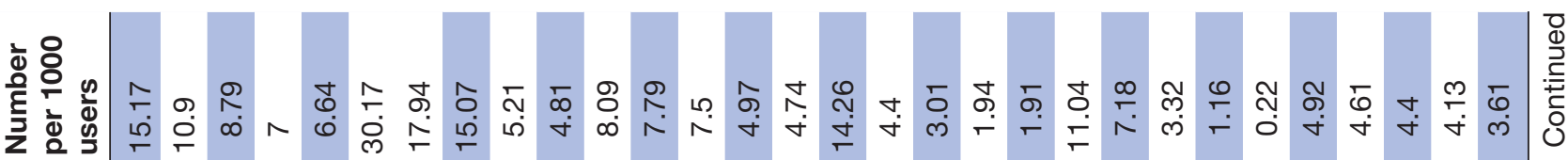

|

$\frac{\substack{\pi \\ \frac{\pi}{5}}}{50}$

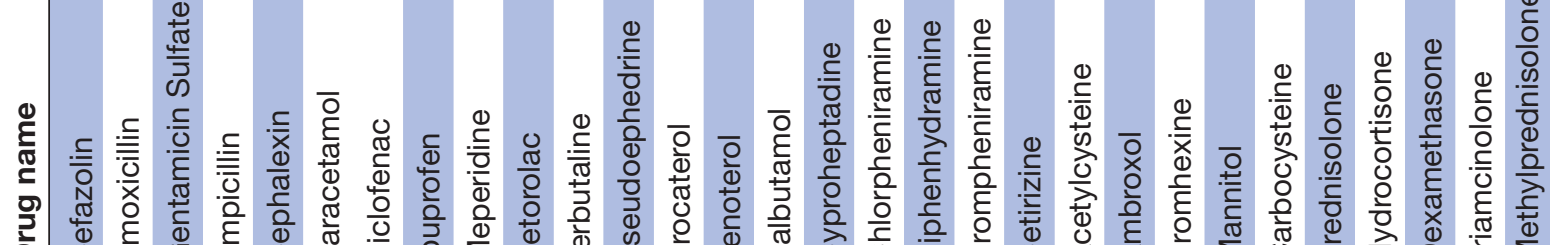

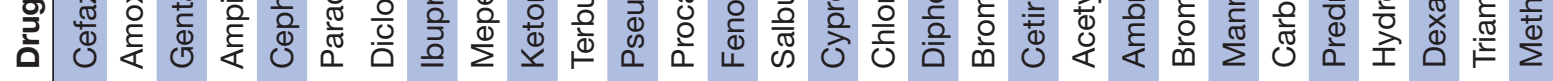

¿

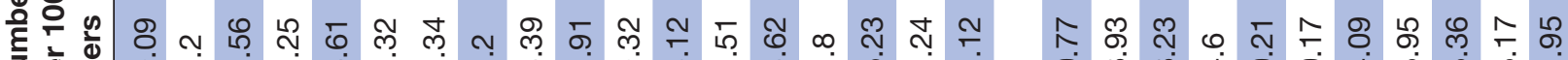

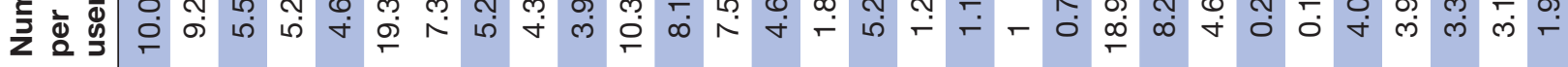

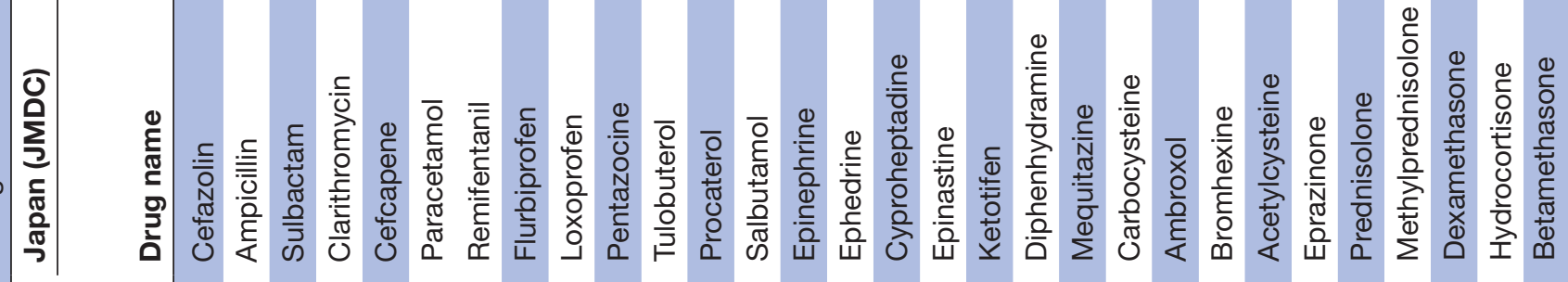

๘

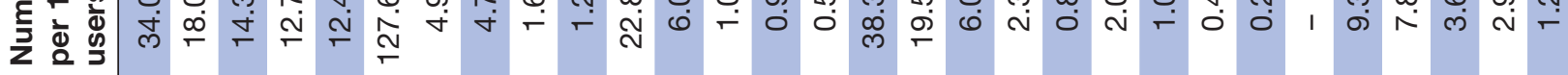

๘

\section{$\underset{\frac{\pi}{5}}{\frac{\pi}{5}}$}

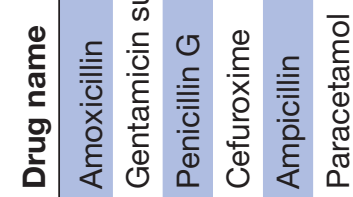

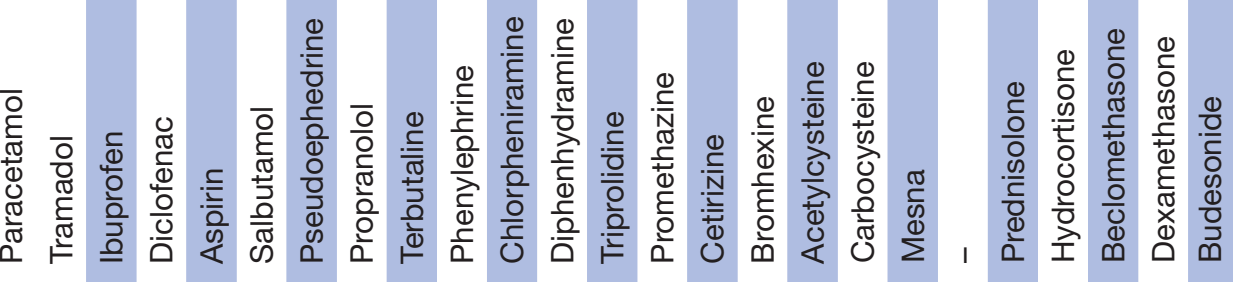

¿

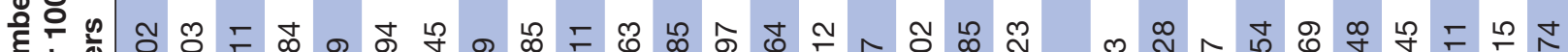
Z ¿

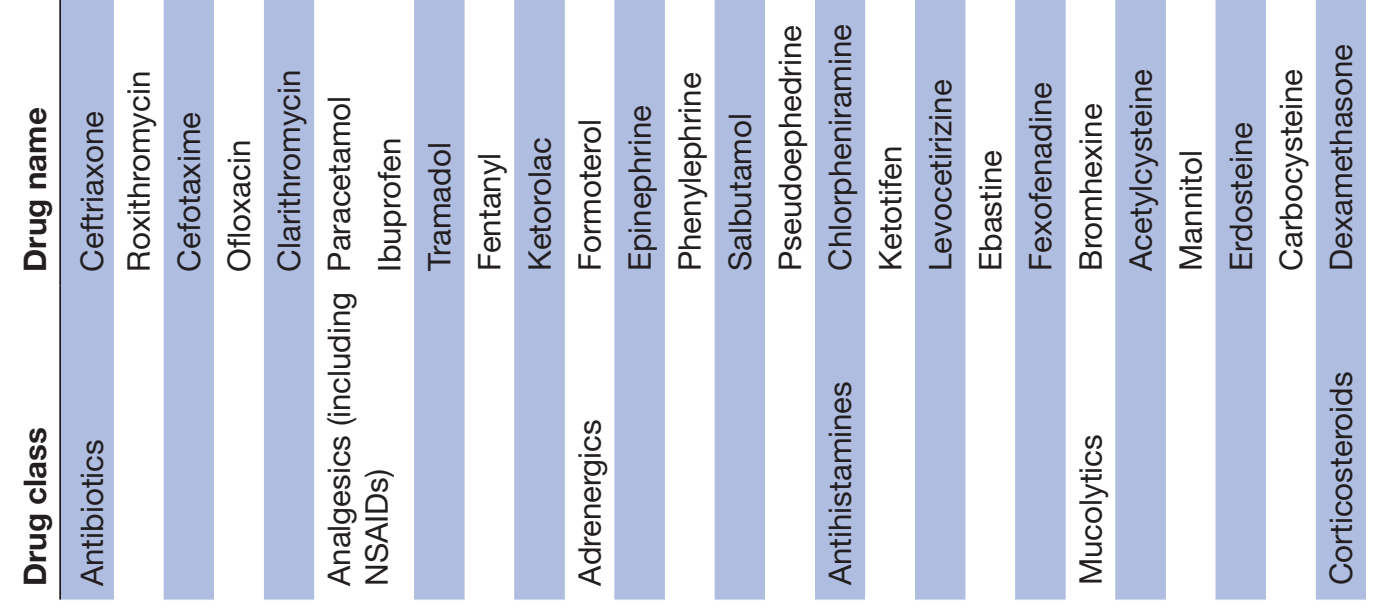




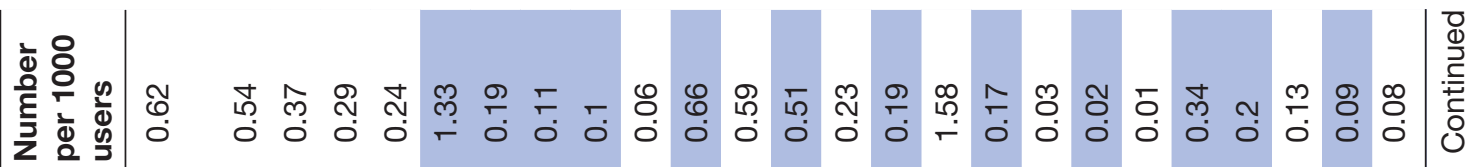

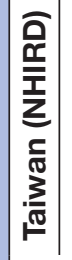

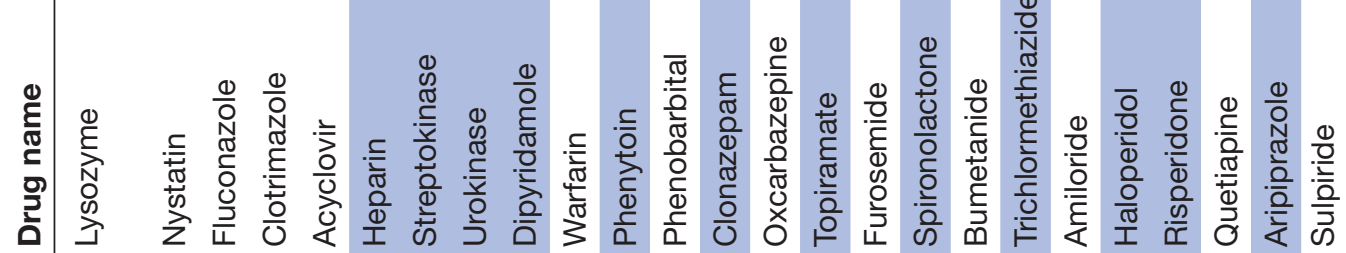
¿

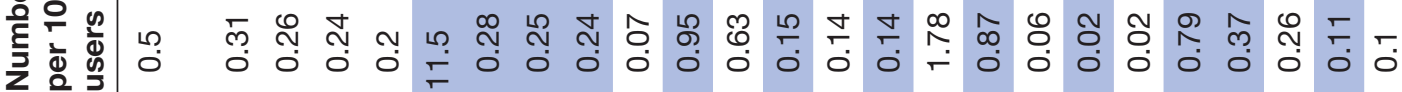

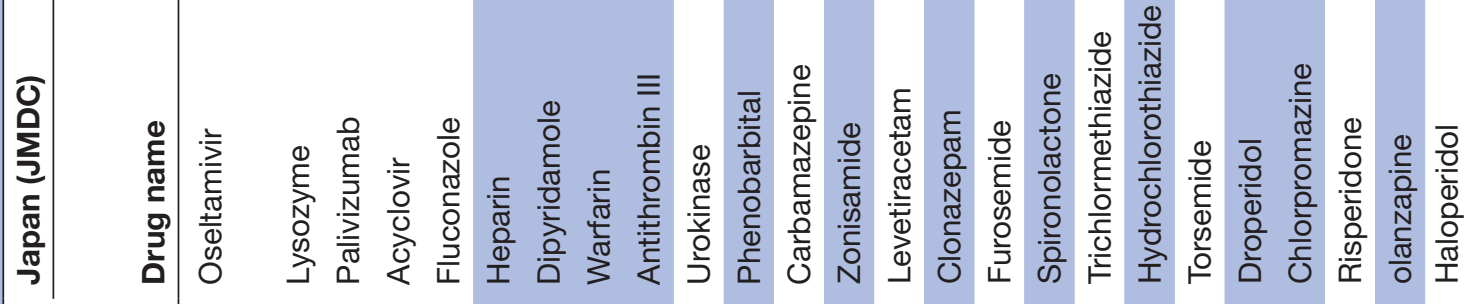

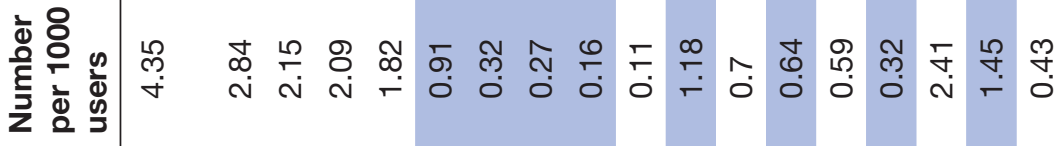
芒

ळ。

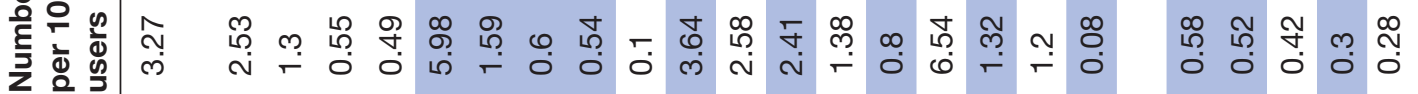

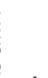

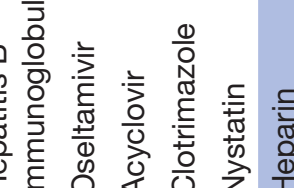

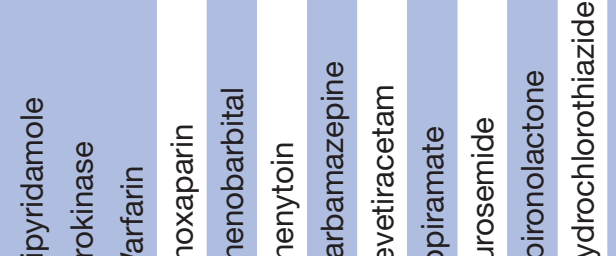

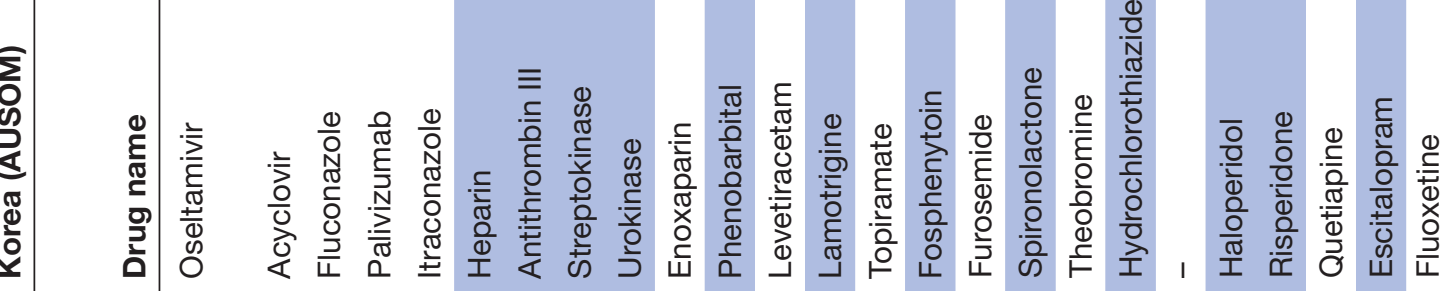
(1)
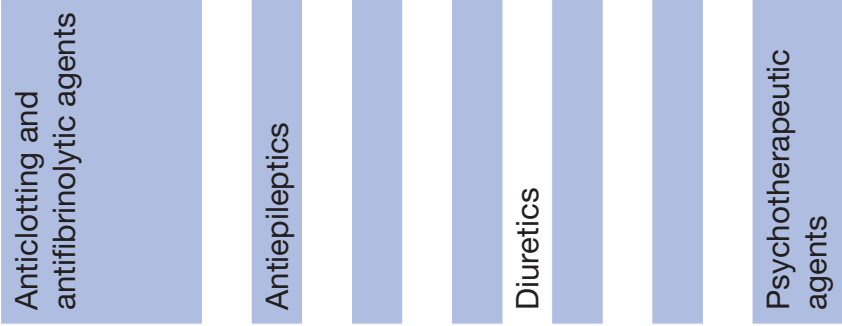


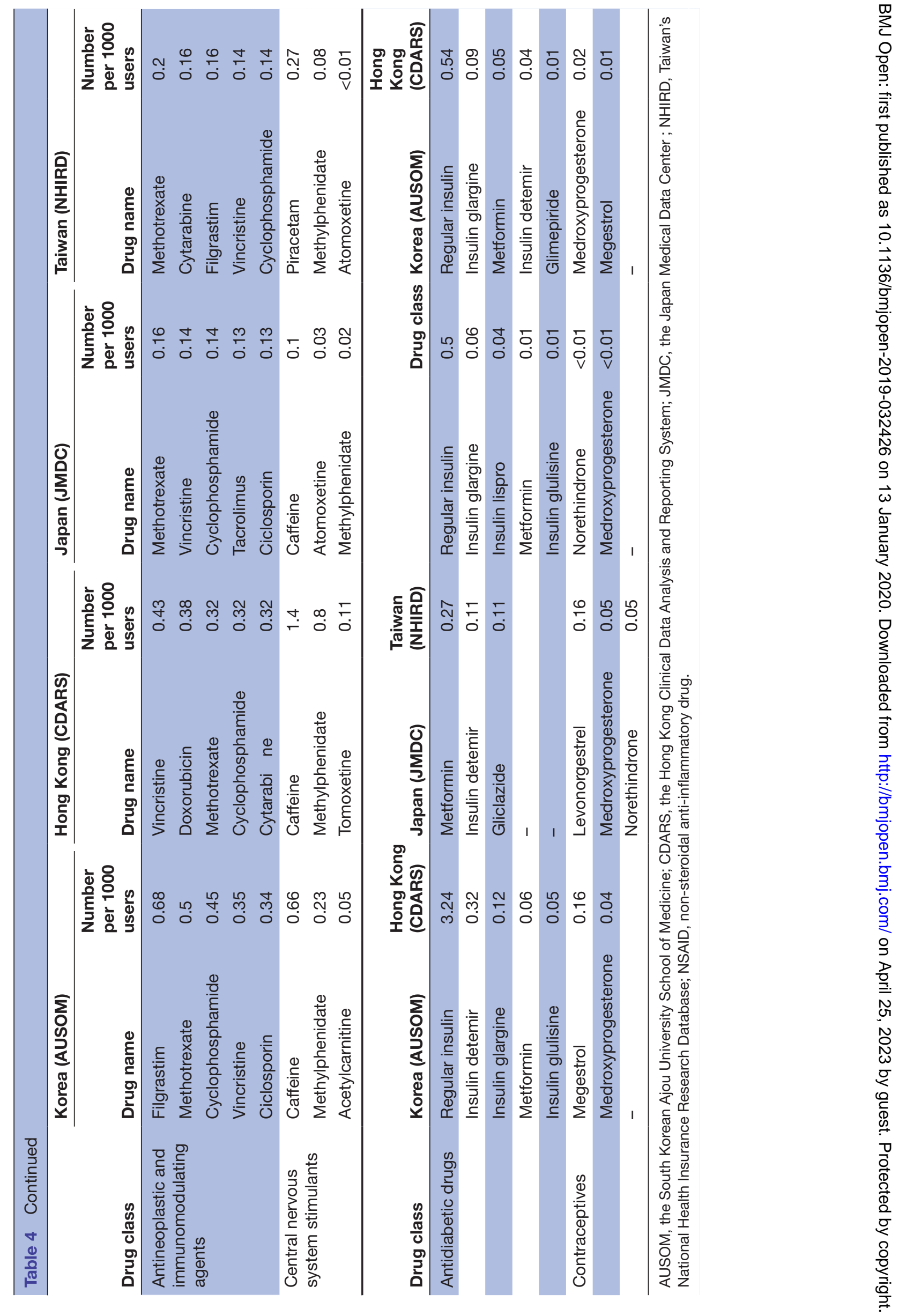


Table 5 Most commonly used drugs per custom-defined drug class, per country, in an ambulatory setting Japan (JMDC)

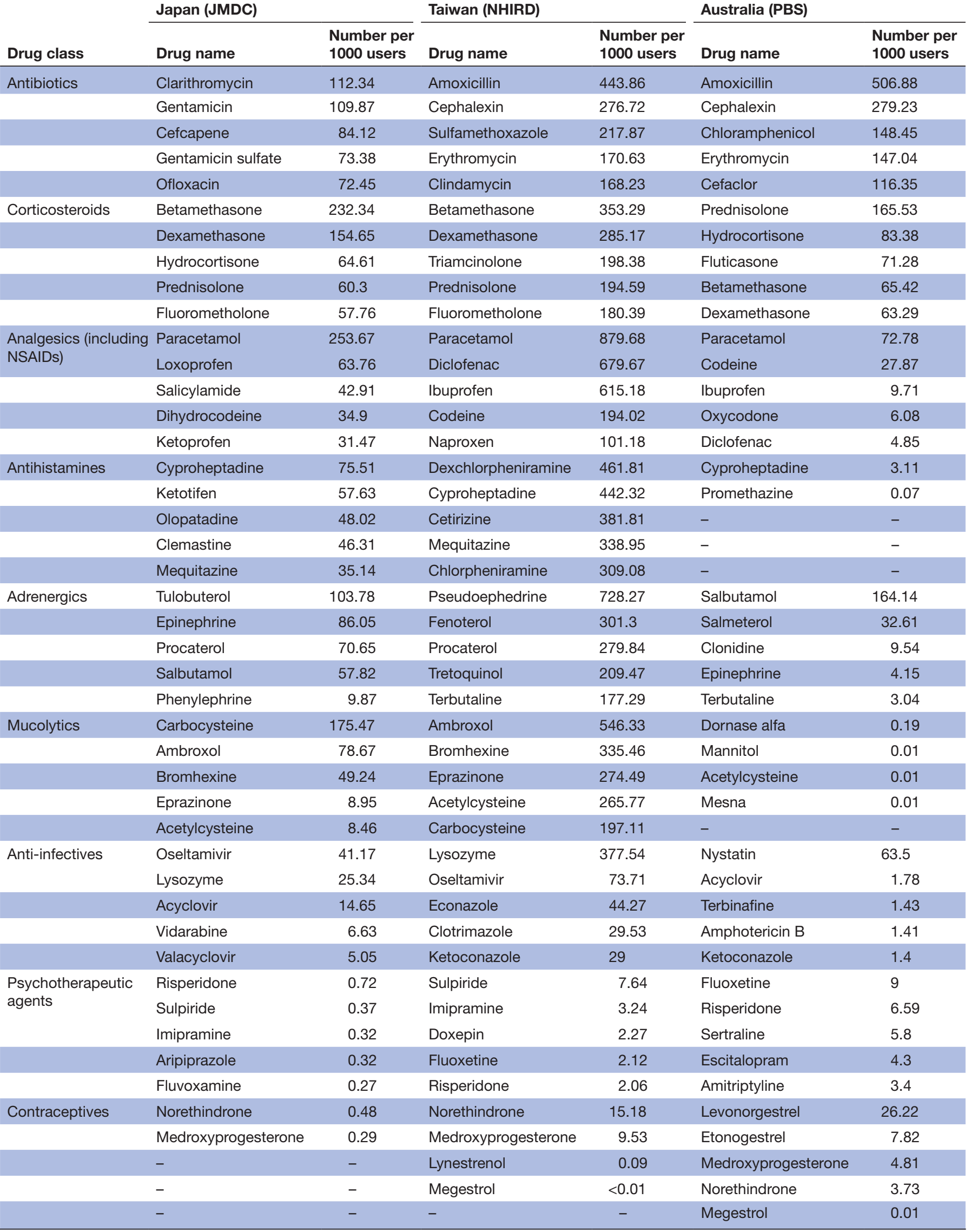

Continued 
Table 5 Continued

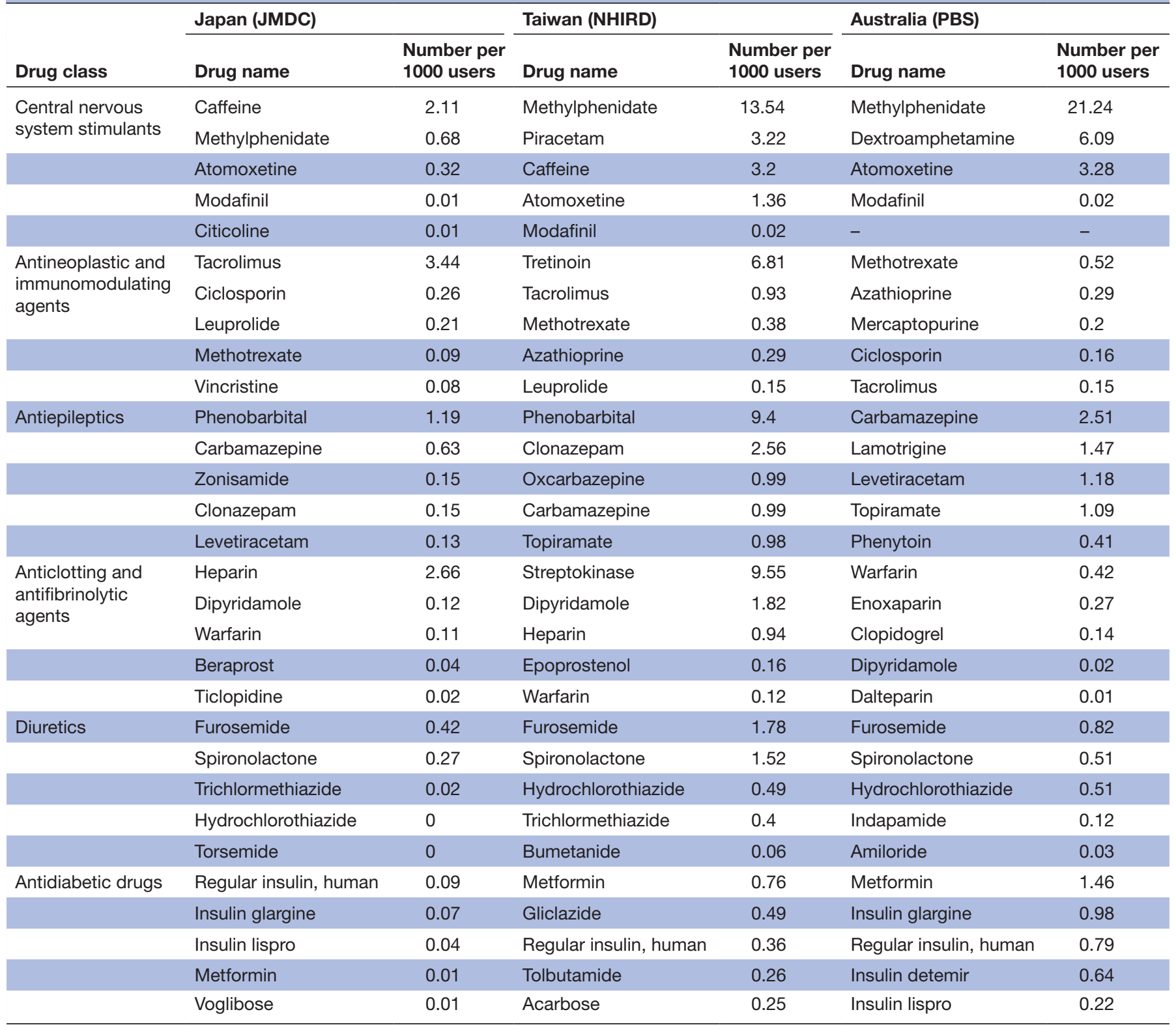

${ }^{*}$ Custom classification, see online supplementary material 1.

JMDC, the Japan Medical Data Center; NHIRD, Taiwan's National Health Insurance Research Database; NSAID, non-steroidal anti-inflammatory drug; PBS, the Australian Pharmaceutical Benefits Scheme.

with results of a study by Rashed $e$ al, who reported on the drug utilisation patterns of children admitted to a paediatric ward in the UK, Germany, Australia, Hong Kong and Malaysia. ${ }^{2}$ As in our study, antibacterials and analgesics were the two most used therapeutic groups in all five countries.

National Korean outpatient data on paediatric polypharmacy show that in paediatric users of two or more drugs (younger than 12 years), respiratory agents are most often prescribed, followed by drugs to treat allergies, central nervous system agents and antibiotics. ${ }^{5}$ While our study was not directly comparable as we had information on Korean inpatient dispensings only, our Taiwanese outpatient data showed a high ambulatory use of analgesics and antihistamines, while Australian and Japanese data showed a high ambulatory use of antibiotics and corticosteroids.

Implications for practice and policy: paediatric licensing of drugs in the Western Pacific region

National agencies responsible for regulating therapeutic goods often base their regulations on international guidelines, especially for new drug licensing. ${ }^{15}{ }^{16}$ For instance, in Korea it is not obligatory to carry out clinical trials for paediatrics and to develop paediatric drugs at present, while various support policies are being developed in recognition of the need for the development and provision of information on paediatric drugs (S. Cho, 2017, 
personal communication). Out of the five countries included in this study, Japan is the only country with a specific paediatric working group within the Pharmaceuticals and Medical Devices Agency. ${ }^{17}$

Results of the current study suggest that the extent to which international paediatric prescribing guidelines affect local prescribing practices differs from country to country. For instance, our study, in line with other studies, shows the widespread of mucolytics in children in Korea, Japan and Taiwan. ${ }^{6}$ This is a finding of note as in 2010 several European drug agencies withdrew the licences for carbocysteine and acetylcysteine for children younger than 2 years of age because their use was associated with worsening of respiratory tract infections. ${ }^{18}$ More recently, the European Medicines Agency (EMA) published a revised assessment report on products containing ambroxol and bromhexine in which the use of these products in children below $<2$ years of age is discouraged. ${ }^{19}$ Our study showed that the use of mucolytics was very high in the youngest age group in all countries but Hong Kong and Australia.

Another drug that is contraindicated for use in children in some European countries is tulobuterol. This drug, a $\beta 2$-agonist, is licensed in seven countries worldwide for childhood asthma. ${ }^{20}$ In 2010, the EMA refused a paediatric investigation plan for tulobuterol and granted a waiver (restricting potential use to patients $>18$ years) as tulobuterol was considered likely to be ineffective or unsafe in the paediatric population. ${ }^{22}$ Yet, in this study tulobuterol was the most used adrenergic agent in an outpatient setting in Japan with $74 \%$ of all tulobuterol prescribed as patches (hokunalin tape) and the remaining $26 \%$ prescribed as a liquid (oral).

A further finding of note was the relatively common ambulatory use of dihydrocodeine in Japan and codeine in Taiwan and Australia. Both codeine and dihydrocodeine are morphine derivatives and are contraindicated for use in children younger than 12 in Europe since $2013{ }^{23}$ This is mainly due to the unpredictable metabolism of codeine to morphine. ${ }^{24}$ At the time of data collection (2009-2012), Australia already had prescribing guidelines in place in which it was recommended to restrict the use of codeine in children under 12 years.

Lastly, we found that sulfamethoxazole is still one of the most used antibiotic agents in Taiwan. In many European countries, including the UK, the importance of the sulfonamides has decreased as a result of increasing bacterial resistance and their replacement by antibacterials which are generally more active and less toxic. ${ }^{25}$

\section{Strengths and limitations}

We conducted the largest Western Pacific paediatric drug utilisation study to date. Data extraction was performed through a shared analysis programme and a standardised analysis process was applied to all databases. Using a CDM, and CDM vocabulary concept identifiers, we were able to use standardised drug codes across countries which allowed us to rank the user and prescription prevalence of 15 different drug classes in 5 different countries. We found some important similarities and differences in country-specific drug utilisation patterns between Korea, Hong Kong, Japan, Taiwan and Australia.

It is important to highlight that our study did not aim to directly compare the drug prevalence rates between the countries in this study, rather we aimed to provide a comprehensive overview of the country-specific pharmacological agents used in both an ambulatory and inpatient setting by gender and age. Differences in user and prescription prevalence patterns between the five countries in our study may reflect differences in the underlying prevalence of diseases, differences in physician prescribing behaviour and differences in medicine availability and data capture. Like other drug utilisation studies using EHR, we could not distinguish between these. Additionally, as medical indications were not available in all data sets we were unable to report the reasons for prescriptions. We acknowledge that this limits the clinical interpretation of our data. Formularies were different across countries as well, particularly with regard to which medicines were subsidised in the data and for which indication. It is also worth noting that we did not distinguish between formulations and we recognise that this limits the clinical interpretation of our data. Lastly, the five databases captured different source populations.

Despite the differences in databases in terms of size, setting and study populations, we believe our overview of prescription patterns and rankings is an important step to further investigate and facilitate the rational use of drugs in paediatric populations in East Asia and Australia. Standardising medication use across countries will help when implementing adverse event monitoring programmes across the region.

Over the counter (OTC) prescribing in individual countries was not captured and we may have underestimated the true drug utilisation of agents, such as paracetamol and some antihistamines. OTC prescribing is most likely to have affected any ambulatory drug utilisation estimates.

Future studies could be conducted using the current dataset in OMOP CDM format to capture any changes in paediatric drug dispensing over time. We collected data until the end of 2013 and acknowledge that, due to the rapid change in paediatric licensing of therapeutic agents, some of our findings might be worthwhile replicating with more current data.

\section{CONCLUSION}

Country-specific paediatric drug utilisation patterns were described, ranked and compared between four East Asian countries and Australia. The widespread use of mucolytics in East Asia and the use of tulobuterol in Japan warrants further investigation. 
Author affiliations

${ }^{1}$ Research Department of Practice and Policy, School of Pharmacy, University College London, London, UK

${ }^{2}$ Centre for Safe Medication Practice and Research, Department of Pharmacology and Pharmacy, University of Hong Kong, Hong Kong, Hong Kong

${ }^{3}$ Quality Use of Medicines and Pharmacy Research Centre, University of South Australia, Adelaide, South Australia, Australia

${ }^{4}$ Department of Biomedical Informatics, Ajou University School of Medicine, Suwon, Republic of Korea

${ }^{5}$ Graduate Institute of Biomedical Informatics, College of Medical Science and Technology, Taiwan Medical University, Taipei, Taiwan

${ }^{6}$ The International Center for Health Information Technology (ICHIT), Taipei Medical University, Taipei, Taiwan

${ }^{7}$ Department of Dermatology, Wan Fang Hospital, Taipei, Taiwan

${ }^{8}$ International Medical Informatics Association (IMIA), Geneva, Switzerland

${ }^{9}$ Masters \& PhD Program in Global Health Department, College of Public Health,

Taipei Medical University, Taipei, Taiwan

${ }^{10}$ Department of Public Health and Community Medicine, Shaikh Khalifa Bin Zayed

Al-Nahyan Medical College, Shaikh Zayed Medical Complex, Lahore, Pakistan

${ }^{11}$ Epidemiology Analytics, Janssen Research and Development, Titusville, New Jersey, USA

${ }^{12}$ Department of Biostatistics, University of California, Los Angeles, California, USA

\section{Twitter Kenneth KC Man @KennethKCMan}

Acknowledgements The analysis is based in part on work from the Observational Health Sciences and Informatics collaborative (OHDSI). OHDSI (http://ohdsi.org) is a multistakeholder, interdisciplinary collaborative to create open-source solutions that bring out the value of observational health data through large-scale analytics.

Contributors MS and ICKW designed the study. MS wrote the protocol for this study and was responsible for the statistical programming. RB wrote the first draft of the manuscript. MS, KKCM, NLP, RWP, S-YC, Y-CL, UI and P-AAN ran countryspecific analyses and contributed original data. All authors contributed to critical revisions of the manuscript. All authors read and approved the final manuscript.

Funding The authors have not declared a specific grant for this research from any funding agency in the public, commercial or not-for-profit sectors. Rae Woong Park was supported by a grant of the Korea Health Technology R\&D Project through the Korea Health Industry Development Institute (KHIDI), funded by the Ministry of Health \& Welfare, Republic of Korea [grant number : Hl16C0992] and the Bio Industrial Strategic Technology Development Program (20003883) funded By the Ministry of Trade, Industry \& Energy (MOTIE, Korea).

Disclaimer MS is an employee of Janssen Research \& Development. None of the remaining authors has financial relationships relevant to this article to disclose.

Competing interests None declared.

Patient consent for publication Not required.

Ethics approval This study received approval from the Institutional Review Board of the University of Hong Kong/Hospital Authority Hong Kong West Cluster (HKU/HA HKW IRB), reference number: UW 13-504.

Provenance and peer review Not commissioned; externally peer reviewed.

Data availability statement № data are available.

Open access This is an open access article distributed in accordance with the Creative Commons Attribution Non Commercial (CC BY-NC 4.0) license, which permits others to distribute, remix, adapt, build upon this work non-commercially, and license their derivative works on different terms, provided the original work is properly cited, appropriate credit is given, any changes made indicated, and the use is non-commercial. See: http://creativecommons.org/licenses/by-nc/4.0/.

\section{ORCID iDs}

Ruth Brauer http://orcid.org/0000-0001-8934-347X

Kenneth KC Man http://orcid.org/0000-0001-8645-1942

Martijn Schuemie http://orcid.org/0000-0002-0817-5361

\section{REFERENCES}

1 Wong ICK, Murray ML. The potential of UK clinical databases in enhancing paediatric medication research. $\mathrm{Br} J$ Clin Pharmacol 2005;59:750-5.
2 Rashed AN, Wong ICK, Wilton L, et al. Drug utilisation patterns in children admitted to a paediatric general medical ward in five countries. Drugs Real World Outcomes 2015;2:397-410.

3 Sturkenboom MCJM, Verhamme KMC, Nicolosi A, et al. Drug use in children: cohort study in three European countries. $B M J$ 2008;337:a2245.

4 Chua KL, Soh SE, Ma S, et al. Pediatric asthma mortality and hospitalization trends across Asia Pacific: relationship with asthma drug utilization patterns. World Allergy Organ J 2009;2:77-82.

5 Jeon S-M, Park S, Rhie SJ, et al. Prescribing patterns of polypharmacy in Korean pediatric patients. PLoS One 2019;14:e0222781.

6 Cheng C-L, Kao Yang Y-H, Liu C-C, et al. A retrospective study on the usage of cough and cold medications in viral respiratory tract infections in Taiwanese children. Pharmacoepidemiol Drug Saf 2014;23:36-42.

7 Lai EC-C, Ryan P, Zhang Y, et al. Applying a common data model to Asian databases for multinational pharmacoepidemiologic studies: opportunities and challenges. Clin Epidemiol 2018;10:875-85.

8 Andersen M, Bergman U, Choi N-K, et al. The Asian pharmacoepidemiology network (aspen): promoting multi-national collaboration for pharmacoepidemiologic research in Asia. Pharmacoepidemiol Drug Saf 2013;22:700-4.

9 Chan EW, Lau WCY, Leung WK, et al. Prevention of DabigatranRelated gastrointestinal bleeding with gastroprotective agents: a population-based study. Gastroenterology 2015;149:586-95.

10 Chui CSL, Man KKC, Cheng C-L, et al. An investigation of the potential association between retinal detachment and oral fluoroquinolones: a self-controlled case series study. J Antimicrob Chemother 2014;69:2563-7.

11 Man KKC, Chan EW, Coghill D, et al. Methylphenidate and the risk of trauma. Pediatrics 2015;135:40-8.

12 Tanaka S, Seto K, Kawakami K. Pharmacoepidemiology in Japan: medical databases and research achievements. J Pharm Health Care Sci $2015 ; 1$

13 Lai EC-C, Man KKC, Chaiyakunapruk N, et al. Brief report: databases in the Asia-Pacific region: the potential for a distributed network approach. Epidemiology 2015;26:815-20.

14 Rose K, Stötter H. ICH E 11: clinical investigation of medicinal products in the paediatric population. In: Rose K, ed. Guide to paediatric clinical research. Basel: KArger, 2007: 33-7.

15 Woo Y, Kim HE, Chung S, et al. Pediatric medication error reports in Korea adverse event reporting system database, 1989-2012: comparing with adult reports. J Korean Med Sci 2015;30:371-7.

16 Taiwan Food and Drugs Administration. Taiwan food and drug administration annual report, 2016. Available: http://www.fda.gov.tw/ upload/ebook/AnnuaReport/2016 [Accessed October 2016].

17 Sato J. Global pediatric development: we are making progress. PMDA Perspective.: Japanese Pharmaceuticals and Medical Devices Agency (PMDA), 2014.

18 Mallet P, Mourdi N, Dubus J-C, et al. Respiratory paradoxical adverse drug reactions associated with acetylcysteine and carbocysteine systemic use in paediatric patients: a national survey. PLoS One 2011;6:e22792.

19 European Medicines Agency (EMA). Revised assessment report: ambroxol and bromhexine containing medicinal products. Available: http://www.ema.europa.eu/docs/en_GB/document library/Referrals document/Ambroxol_and_bromhexine_31/Recommendation provided_by_Pharmacovigilance_Risk_Assessment_Committee/ WC500184106.pdf [Accessed 10 Sep 2015].

20 Schmiedl S, Fischer R, Ibáñez L, et al. Utilisation and offlabel prescriptions of respiratory drugs in children. PLoS One 2014;9:e105110.

21 Arakawa H, Hamasaki Y, Kohno Y, et al. Japanese guidelines for childhood asthma 2017. Allergol Int 2017;66:190-204.

22 European Medicines Agency (EMA). Opinion of the paediatric Committee on the refusal of a paediatric investigation plan and on the granting of a product-specific waiver. Available: http://www. ema.europa.eu/docs/en_GB/document_library/PIP_decision/ WC500095327.pdf [Accessed 27 Feb 2017]

23 European Medicines Agency (EMA). Assessment report: codeine containing medicinal products for the treatment of cough and/or cold in paediatric patients. Available: http://www.ema.europa.eu/docs/en GB/document_library/Referrals_document/Codeine_cough_or_cold_ in_children/Recommendation_provided_by_Pharmacovigilance Risk_Assessment_Committee/WC500186522.pdf [Accessed 12 Mar 2015].

24 Ciszkowski C, Madadi P, Phillips MS, et al. Codeine, ultrarapidmetabolism genotype, and postoperative death. N Engl J Med 2009;361:827-8. 
25 British National Formulary (BNF). Clarithromycin. Available: https:// www.evidence.nhs.uk/formulary/bnf/current/5-infections/51- antibacterial-drugs/515-macrolides/clarithromycin [Accessed 30 Mar 2017]. 